\title{
Intra- versus interchain interactions in $\alpha, \omega$-polyamines: a Raman spectroscopy study
}

\author{
A.M. Amorim da Costa $^{\text {a, }}$, M.P.M. Marques ${ }^{\mathrm{a}, \mathrm{b}}$, L.A.E. Batista de Carvalho ${ }^{\mathrm{a}}$ \\ aUnidade I \& D "Química-Física Molecular”, Coimbra, Portugal \\ ${ }^{\mathrm{b}}$ Biochemistry Department, Faculty of Sciences and Technology, University of Coimbra, 3000 Coimbra, Portugal
}

Received 10 October 2003; received in revised form 8 January 2004; accepted 14 January 2004

Available online 5 March 2004

\begin{abstract}
Raman spectroscopy is used to examine the intra- and interchain interactions in aliphatic diamines $\mathrm{H}_{2} \mathrm{~N}\left(\mathrm{CH}_{2}\right)_{n} \mathrm{NH}_{2}(n=2-10$ and 12$)$ and their $\mathrm{N}$-deuterated derivatives, either as a function of chainlength or as a function of temperature. The intensity of the in-phase $\mathrm{C}-\mathrm{C}$ stretching mode divided by the integrated area of the $\mathrm{N}-\mathrm{H}$ or the $\mathrm{N}-\mathrm{D}$ stretching regions is discussed as a parameter which can be used as a quantitative measure of the average number of trans bonds in the hydrocarbon chain, while the relative intensity of the $\mathrm{C}-\mathrm{H}$ antisymmetric and symmetric stretching vibrations is used as a measure of the lateral packing effects of the hydrocarbon chains.
\end{abstract}

(C) 2004 Elsevier B.V. All rights reserved.

Keywords: Aliphatic diamines; Raman spectroscopy

\section{Introduction}

The conformational preferences of linear chain systems, such as $n$-alkanes or lipid bilayers, are determined by the relative importance of both intra- and interchain interactions. Raman spectroscopy experiments, coupled to normal coordinate analysis, allow the use of the relative intensity of the band assigned to the totally symmetric $\mathrm{C}-\mathrm{C}$ stretching mode, as an order-parameter which gives a quantitative measure of the trans to gauche orientations within those systems [1-3]. Moreover, in order to study the environment interactions-both lateral packing and top-to-end-special attention should be paid to the changes observed in the $\mathrm{C}-\mathrm{H}$ stretching region. In fact, for hydrocarbon chains it has been observed that while the band due to the methylene $\mathrm{C}-\mathrm{H}$ antisymmetric mode broadens, loses intensity and shifts to higher frequencies, as the intermolecular lateral interactions decrease, the symmetric stretching one remains sharp as well as the most intense feature in the spectrum [2,4]. A quantitative measure of this lateral order was thus developed [2], as a function of the relative observed intensity of the $\mathrm{C}-\mathrm{H}$ symmetric and antisymmetric stretching bands.

\footnotetext{
* Corresponding author. Present address: Department of Chemistry, Faculty of Sciences and Technology, University of Coimbra, Coimbra Codex P-3000, Portugal. Tel.: +351-239-82-65-41; fax: +351-239-82-65-41. E-mail address: acosta@ci.uc.pt (A.M. Amorim da Costa).
}

In the present work, both the $\mathrm{C}-\mathrm{C}$ and the $\mathrm{C}-\mathrm{H}$ stretching vibrations of aliphatic diamines $\mathrm{H}_{2} \mathrm{~N}\left(\mathrm{CH}_{2}\right)_{n} \mathrm{NH}_{2}(n=2-10$ and 12) will be analysed, focusing on the occurrence of intra- and intermolecular interactions. Some of these amines are the precursors of biogenic polyamines such as spermidine and spermine, which are present in all eukaryotic organisms, being essential for cell growth and differentiation. Although the exact nature of the biochemical mechanism through which these linear amines act in the living cell is still unknown, the relative importance of intra- and intermolecular interactions has proved to be of the utmost importance in determining the conformational preferences of this kind of systems [5-8].

\section{Experimental}

The Raman spectra performed at room temperature were obtained on a Spex Ramalog 1403 double spectrometer (focal distance $0.85 \mathrm{~m}$, aperture $f / 7.8$ ) equipped with holographic gratings of 1800 grooves $\mathrm{mm}^{-1}$ and a detector assembly containing a thermoelectrically cooled Hamamatsu R928 photomultiplier tube. The spectrometer operated with slits of 320 $\mu \mathrm{m}$ and $1 \mathrm{~cm}^{-1} \mathrm{~s}^{-1}$. For varying temperature studies, a homemade Harney-Miller type assembly was used, in a triple monochromator Jobin-Yvon T64000 Raman system $(0.640 \mathrm{~m}$, f/7.5) with holographic gratings of 1800 grooves $\mathrm{mm}^{-1}$. 
The detection system was a non-intensified charge coupled device (CCD) and the entrance slit was set to $300 \mu \mathrm{m}$.

The $514.5 \mathrm{~nm}$ line of an $\mathrm{Ar}^{+}$laser (Coherent, model Innova 300) was used as excitation radiation, providing 100-120 mW at the sample position. Samples were sealed in Kimax glass capillary tubes of $0.8 \mathrm{~mm}$ i.d. Under the above mentioned conditions, the error in wavenumbers was estimated to be within $1 \mathrm{~cm}^{-1}$, while the error in temperatures was less than $1 \mathrm{~K}$.

The $\mathrm{N}-\mathrm{H} \alpha, \omega$-aliphatic polyamines were purchased from Sigma-Aldrich (Sintra, Portugal). The corresponding deuterated compounds were obtained by solubilization of the amines in $\mathrm{D}_{2} \mathrm{O}$ (ca. $10 \%$ excess) followed by distillation under vacuum (this process being repeated at least three times). Purification of the samples was carried out shortly before running the Raman spectra. The solid amines were purified by sublimation, while the liquids were distilled under vacuum. Air or moisture sensitive samples (both the $\mathrm{N}-\mathrm{H}$ and the $\mathrm{N}-\mathrm{D}$ amines) were always handled in a glovebox, under a nitrogen or argon atmosphere.

\section{Results and discussion}

\subsection{The intensity changes of the $C-C$ stretching mode and the average number of trans bonds}

In $n$-alkanes and lipid hydrocarbon chains, the skeletal $\mathrm{C}-\mathrm{C}$ stretching vibration in which the alternate carbon atoms move in opposite direction appear in the $1000-1200 \mathrm{~cm}^{-1}$ region. For an extended chain with all-trans structures, there are two intense bands in this region: one at ca. $1064 \mathrm{~cm}^{-1}$ and another around $1130 \mathrm{~cm}^{-1}$. These bands have been assigned to the symmetric or in-phase $\mathrm{C}-\mathrm{C}$ stretching and the antisymmetric $\mathrm{C}-\mathrm{C}$ stretching, respectively, of the fully extended chain [9] which are known to undergo a increase in intensity with the increase of the average number of trans bonds into the chain [10]. In fact, assuming that each trans $\mathrm{C}-\mathrm{C}$ bond, in a sequence of at least three, makes a constant intensity contribution to this $\mathrm{C}-\mathrm{C}$ stretching vibration, Gaber and Peticolas [2] have interpreted its Raman intensity in terms of the probability $P_{\mathrm{t}}$ of the occurrence of a trans bond given by

$I_{\mathrm{R}}=I_{0} \sum n C_{n} P_{\mathrm{t}}$

where $n$ is the number of bonds in an all-trans sequence within a molecule of $\mathrm{N}$ bonds and $\mathrm{C}_{n}$ is the number of times the $n$th segment reoccurs. The sum goes from $n=3$ to N. $I_{\mathrm{R}}$ is the total Raman intensity and $I_{0}$ is the intensity per transunit. This formalism is approximate in assuming $I_{0}$ a constant without regard to neighbour and end group effects. Under this formalism, the Raman intensity of the $\mathrm{C}-\mathrm{C}$ stretching mode of hydrocarbon chains, properly normalized, can be used as a quantitative measure of the average number of trans bonds.
In the application of this formalism, there have been differing treatments to the examination of the experimental data in order to get the aimed information on the chain ordering. Actually, the intensities of the in-phase $\mathrm{C}-\mathrm{C}$ stretching mode were measured either as the peak height of the band decomposed from its broader neighbouring [2] or as the band area [3]. The intensity ratios have also been calculated with respect to different internal standards. For instance, in the study of phosphatidylcholines, the Raman band at $718 \mathrm{~cm}^{-1}$ assigned to a $\mathrm{C}-\mathrm{N}$ stretching mode found to be temperature invariant; or the band at $1090 \mathrm{~cm}^{-1}$ have been used as internal references [2,3]; but in the study of $n-\mathrm{C}_{21} \mathrm{H}_{44}$ in its transition from the orthorhombic to the hexagonal crystalline phase in relation to conformational disorder in lipid bilayers, Snyder et al. [1] have measured the intensity ratio of the in-phase $\mathrm{C}-\mathrm{C}$ stretching mode in two different ways. In the first, the $n-\mathrm{C}_{21} \mathrm{H}_{44}$ was mechanically mixed with $\mathrm{K}_{2} \mathrm{SO}_{4}$ and the $986 \mathrm{~cm}^{-1}$ band of $\mathrm{K}_{2} \mathrm{SO}_{4}$ was used as an intensity reference. In the second, the integrated intensity of the entire C-H stretching region $\left(2800-3000 \mathrm{~cm}^{-1}\right)$ of $n-\mathrm{C}_{21} \mathrm{H}_{44}$ which was found to remain constant to within a few percent in going from the solid to the liquid state, and was used as the internal reference. The results of both sets of measurements were found to be in excellent accord.

In the study of $\alpha, \omega-\mathrm{N}-\mathrm{H}_{2}$ and $\alpha, \omega-\mathrm{N}-\mathrm{D}_{2}$ aliphatic diamines, the in-phase $\mathrm{C}-\mathrm{C}$ stretching mode was assigned to the band at $\sim 1060 \mathrm{~cm}^{-1}$, shown in Fig. 1 for solid propane, pentane, octane and dodecane diamines. Looking for an internal standard for measuring its intensity changes in going from one diamine to another, and its temperature variation for the same diamine, we have used its integrated area calculated from a lorentzian fit related to the integrated area of the entire N-H $\left(3110-3360 \mathrm{~cm}^{-1}\right)$ and N-D (2250$2550 \mathrm{~cm}^{-1}$ ) stretching regions, respectively. Like the observed for the integrated areas of the $\mathrm{C}-\mathrm{H}$ stretching regions of $n$-alkanes [4], also the integrated areas of those stretching regions were found to remain constants to within a few percent, either for the different studied diamines, or for the same diamine, at different temperatures.

As it is shown in Figs. 2 and 3, the ratio of those integrated areas clearly increases with increasing chainlength and from the liquid to the solid, in the case of the same chainlength, as registered for 1,6-diaminohexane. At corresponding temperatures, in the same physical state, there is an increase in the average number of trans bonds with the increasing number of $\mathrm{C}-\mathrm{C}$ bonds from 1,2-diaminoethane to 1,12-diaminododecane. For the same hydrocarbon chain, such an average number decreases as the temperature increases, with an abrupt reduction on going from the solid to the liquid.

From these results it appears that in aliphatic amines the Raman intensity of the in-phase $\mathrm{C}-\mathrm{C}$ stretching mode can be used as an order parameter. However, it does not seem to be a linear relationship between the exact number of trans bonds and its relative Raman intensity. Such a situation does not allow excluding some contribution of gauche bonds to the total intensity of this $\mathrm{C}-\mathrm{C}$ vibrational mode. Rather than 


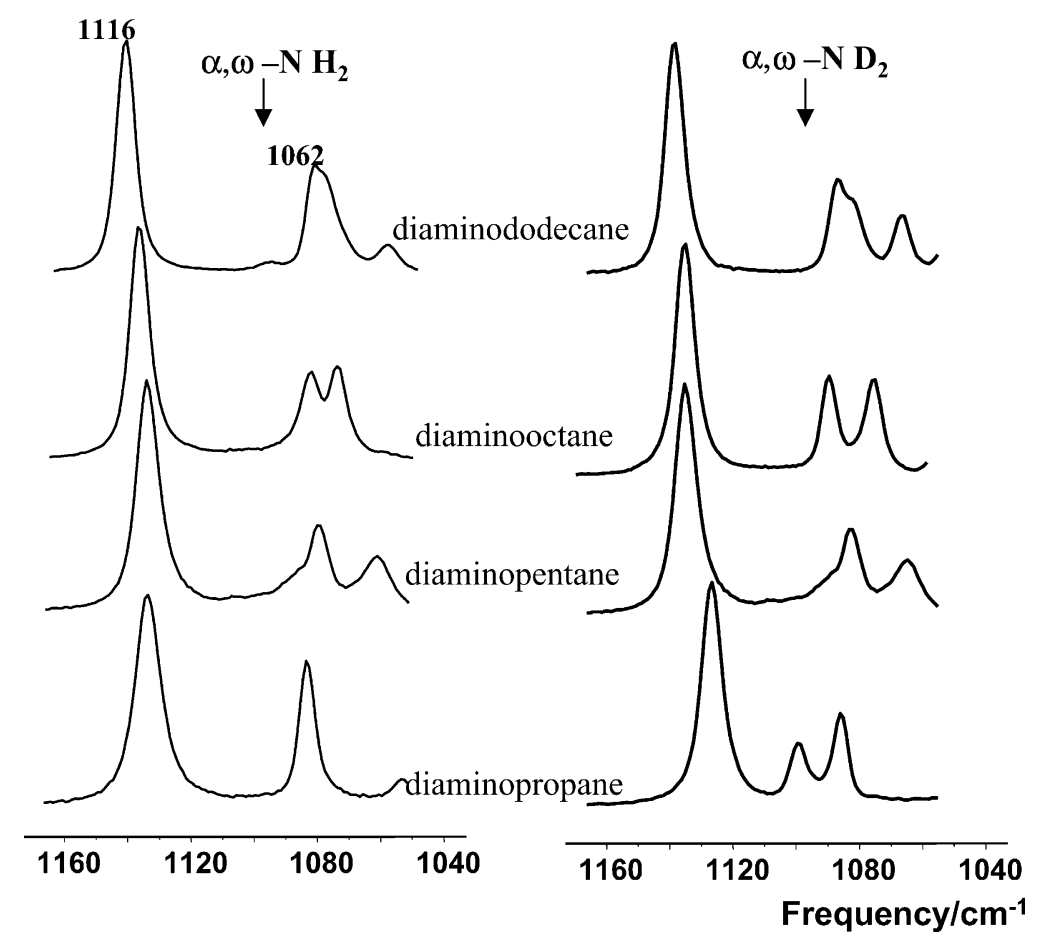

Fig. 1. The $\mathrm{C}-\mathrm{C}$ stretching Raman region for solid $\mathrm{N}-\mathrm{H}_{2}$ and $\mathrm{N}-\mathrm{D}_{2}$ 1,3-diaminopropane; 1,5-diaminopentane; 1,8-diaminooctane; and 1,12diaminododecane.

rigorous quantitative information concerning the number of trans bonds, this intensity provides qualitative information on the fluidity of the hydrocarbon chains. The number of trans and gauche bond content or chain conformations cannot be determined unequivocally from its simple relative intensity measurements.
The same conclusions about this order parameter have already been discussed and advanced for hydrocarbon chain ordering in $n$-alkanes and phospholipid systems. [3] (and references therein). Information about hydrocarbon chain and mobility in aliphatic diamine systems can be dealt with in a similar way.

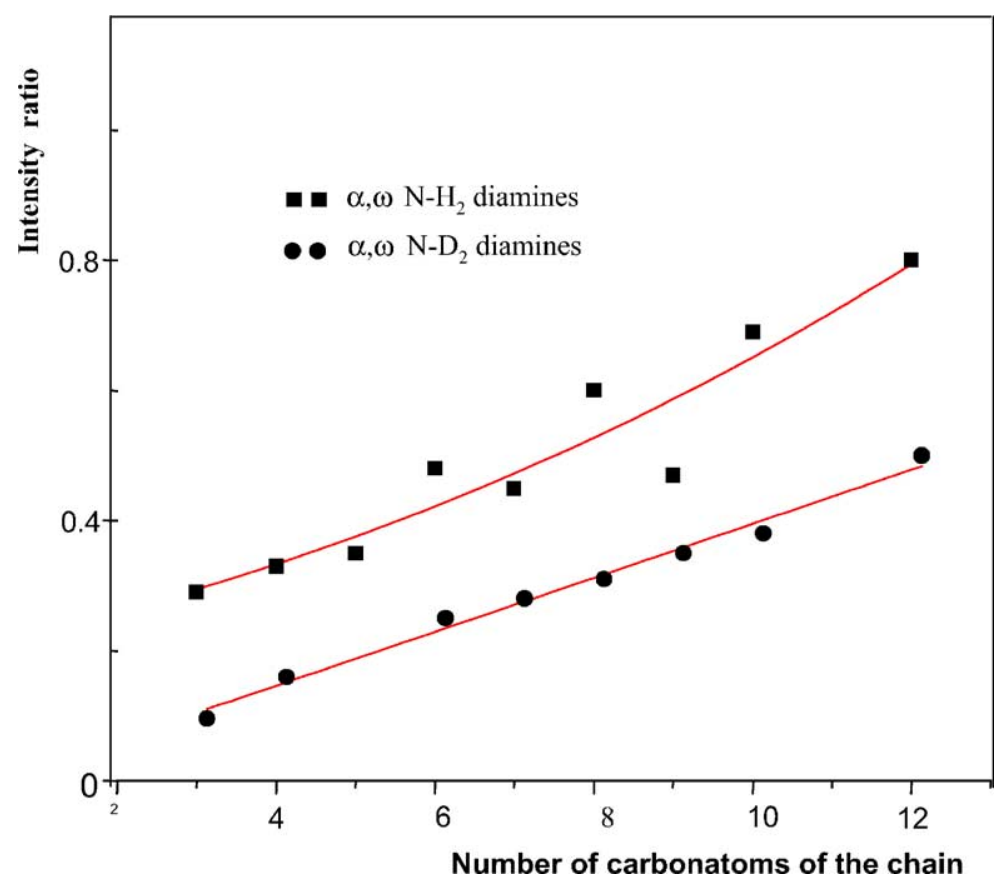

Fig. 2. The integrated area of the in-phase $\mathrm{C}-\mathrm{C}$ stretching mode of $\alpha, \omega-\mathrm{N}-\mathrm{H}_{2}$ and $\alpha, \omega-\mathrm{N}-\mathrm{D}_{2}$ diamines related to the integrated area of the $\mathrm{N}-\mathrm{H}_{2}$ or the $\mathrm{N}-\mathrm{D}_{2}$ stretching regions as a function of the number of $\mathrm{CH}_{2}$ groups in the aliphatic chain. 


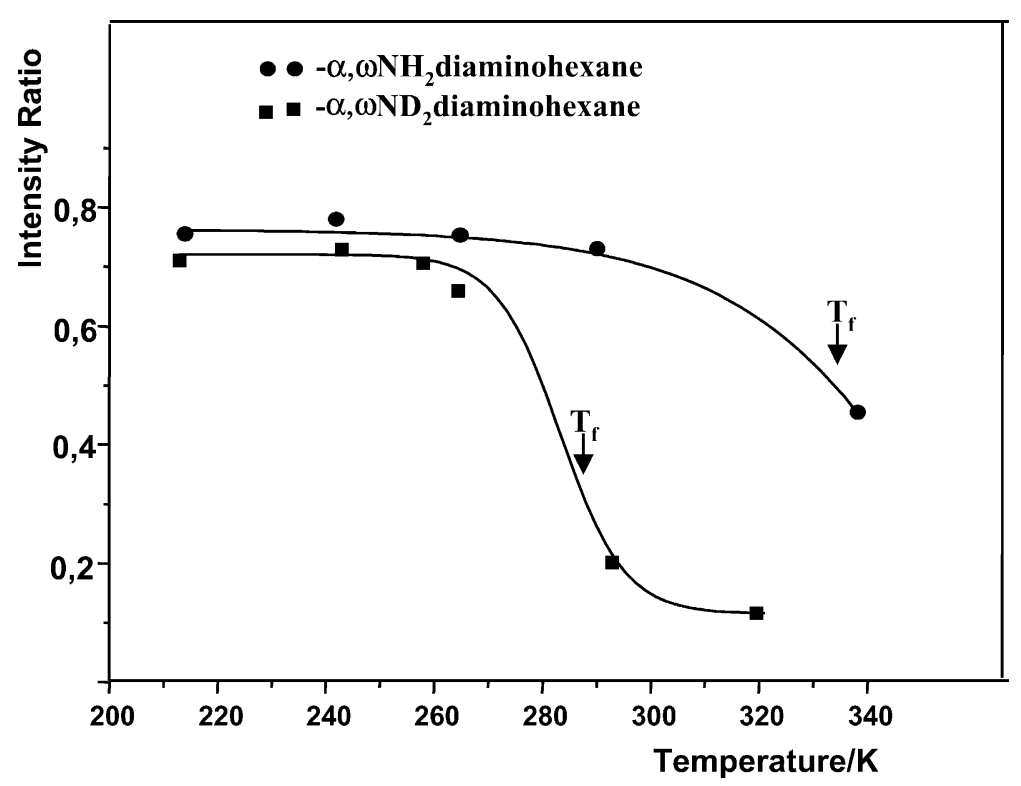

Fig. 3. The integrated area of the in-phase $\mathrm{C}-\mathrm{C}$ stretching mode of $\mathrm{N}-\mathrm{H}_{2}$ and $\mathrm{N}-\mathrm{D}_{2} 1,6$ diaminohexane related to the integrated area of the $\mathrm{N}-\mathrm{H}_{2}$ or the $\mathrm{N}-\mathrm{D}_{2}$ stretching regions as a function of temperature.

\subsection{The intensity of the $C-H$ stretching modes and the} lateral packing order

The observed spectral features of the $\mathrm{C}-\mathrm{H}$ stretching region for solid aliphatic $\alpha, \omega-\mathrm{N}-\mathrm{H}_{2}$ and $\alpha, \omega-\mathrm{N}-\mathrm{D}_{2}$ diamines are presented in Figs. 4 and 5. The analysis of these features shows only small changes either in the number or in the frequencies of the observed bands in the case of the solid aliphatic amines with more than two $\mathrm{CH}_{2}$ groups. Moreover, for these diamines, the deuteration of the $\mathrm{NH}_{2}$ groups has no significant effects on the frequencies and number of bands associated with the stretching vibrations of the methylene

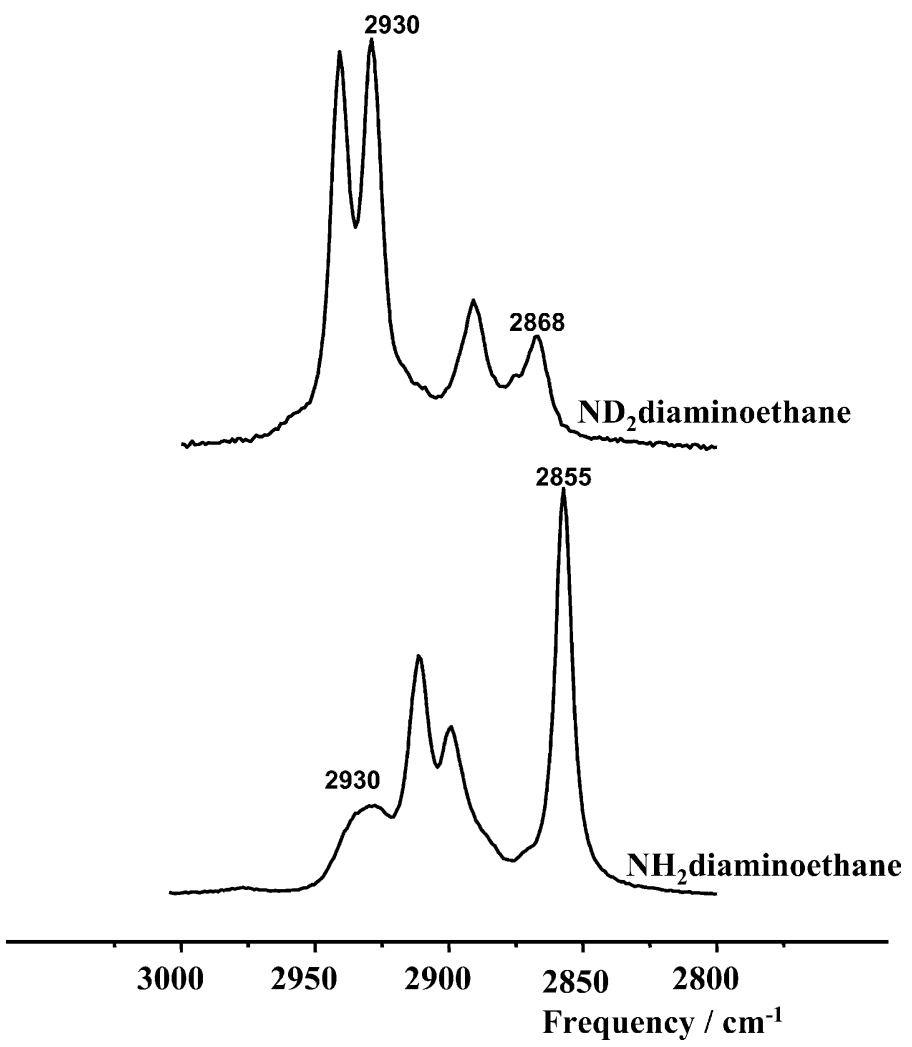

Fig. 4. The $\mathrm{C}-\mathrm{H}$ stretching Raman region for solid $\mathrm{N}-\mathrm{H}_{2}$ and $\mathrm{N}-\mathrm{D}_{2}$ 1,2-diaminoethane. 

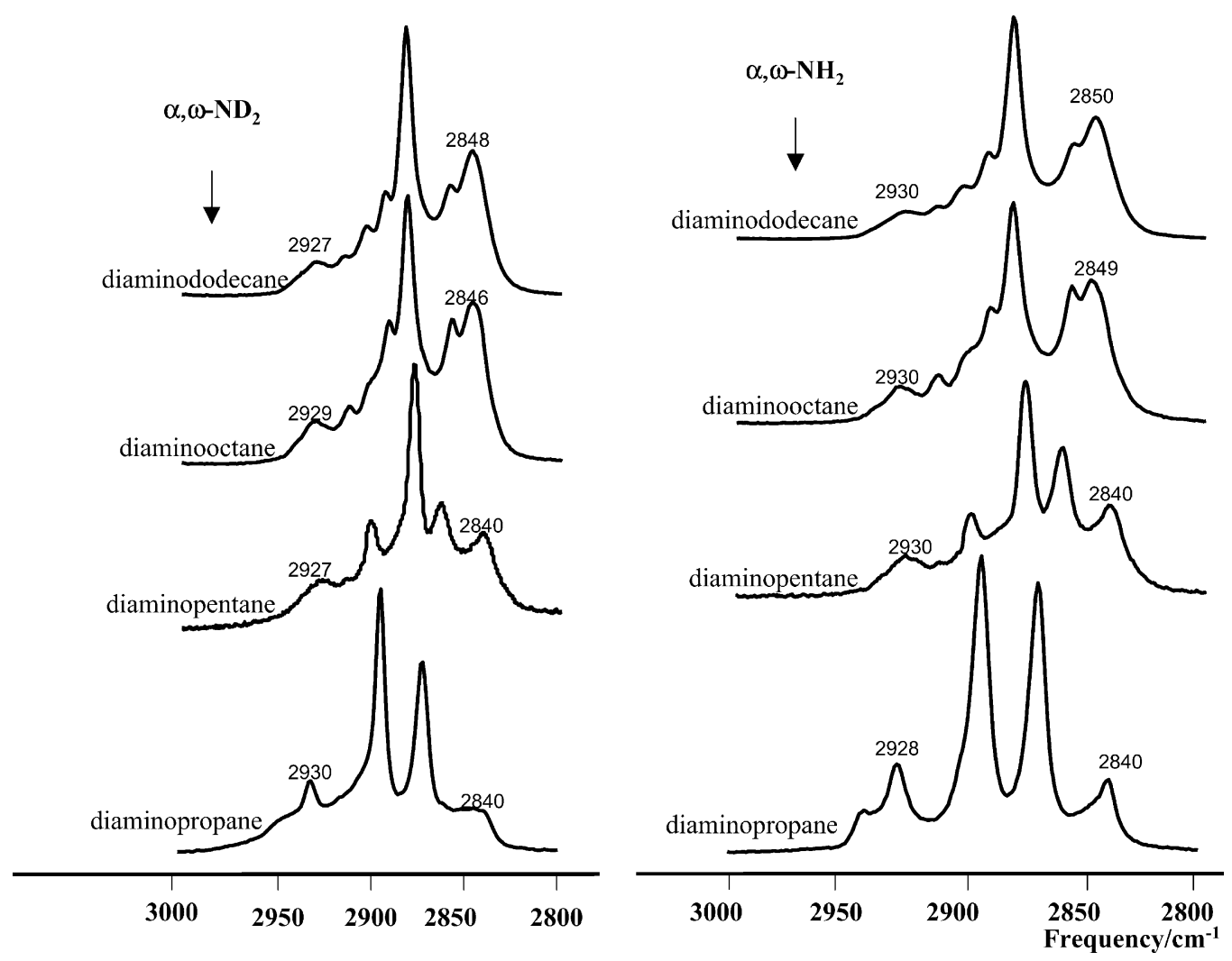

Fig. 5. The C-H stretching Raman region for solid N-H and N-D 1,3-diaminopropane; 1,5-diaminopentane; 1,8-diaminooctane; and 1,12-diaminododecane.

groups [7]. Not so for the 1,2-diaminoethane. In fact, as compared with the $\mathrm{C}-\mathrm{H}$ stretching region of the aliphatic diamines with more than two $\mathrm{CH}_{2}$ groups, the $\mathrm{C}-\mathrm{H}$ stretching region the diaminoethane presents striking differences in the number, relative intensities and frequencies of the observed bands. And upon deuteration of its $\mathrm{NH}_{2}$ groups there are great changes in the frequency and in the relative intensities of those bands.

Several FTIR and Raman studies have already been reported for this simplest linear diamine, the 1,2-diaminoethane, and its $\mathrm{N}$-deuterated derivatives $[11,12]$. In the solid state, this molecule has an all-trans geometry where the two methylene groups are totally equivalent and undistinguable in relation to the end amino groups. Directly bonded to the amino groups, the mass effect upon deuteration and the different strength of the intramolecular $-\mathrm{NH} \ldots \mathrm{N}$ and $-\mathrm{ND} \ldots \mathrm{N}$ hydrogen bonds which can occur in the $\mathrm{NH}_{2}{ }^{-}$ diaminoethane and in the $\mathrm{ND}_{2}$-diaminoethane can explain the observed differences. As the number of methylene groups in the hydrocarbon chain increases, the effect of these intramolecular hydrogen bonds decreases due to the greater separation between the end $\mathrm{NH}_{2}$ or $\mathrm{ND}_{2}$ amino groups. The broadening of the observed bands is expected as the number of $\mathrm{CH}_{2}$ groups increases breaking down the totally equivalent chemical environment [13]. Further studies on the extent of this kind of $-\mathrm{NH} \ldots \mathrm{N}$ and ND ... N interactions in these $\alpha, \omega$-polyamines have been carried out by FTIR spectroscopy and quantum mechanical calculations [5-8].
The relative intensities of the $\mathrm{C}-\mathrm{H}$ stretching bands have also been widely used to probe the conformation, environment and dynamics of hydrocarbon chains assemblies in $n$-alkanes and phospholipid systems. In fact, from calculated frequency-phase difference curves, plotted for the $\mathrm{CH}_{2}$ symmetric and antisymmetric stretching vibrations of $n$ alkanes, it was concluded that the Raman band corresponding to the antisymmetric mode is superimposed to a broad, non-negligible, background signal due to $\mathrm{CH}_{2}$ scissoring overtones intensified through Fermi resonance interaction with the methylene in-phase $\mathrm{C}-\mathrm{H}$ stretching fundamental [14]. Thus, even small frequency changes in the methylene scissoring fundamental upon formation of gauche isomers lead to the removal of this resonance condition, which results in a decrease of the observed maximum of the feature comprising both the overtones (broad signal) and the superimposed, intense, narrow $\mathrm{C}-\mathrm{H}$ antisymmetric stretching band, but hardly affecting the intensity of the corresponding symmetric mode [14-18].

Breaking the total relative intensity of the $\mathrm{C}-\mathrm{H}$ antisymmetric stretching band versus the symmetric stretching band of a highly crystalline hydrocarbon chain into (i) the residual intensity in the liquid (0.7), (ii) the difference between the intensity of a liquid and that of an isolated all-trans chain and (iii) the intensity due to vibrational coupling between the adjacent chains, the so-called lateral interactions, Gaber and Peticolas have developed an order parameter to distinguish as much as possible between the order due to intrachain 


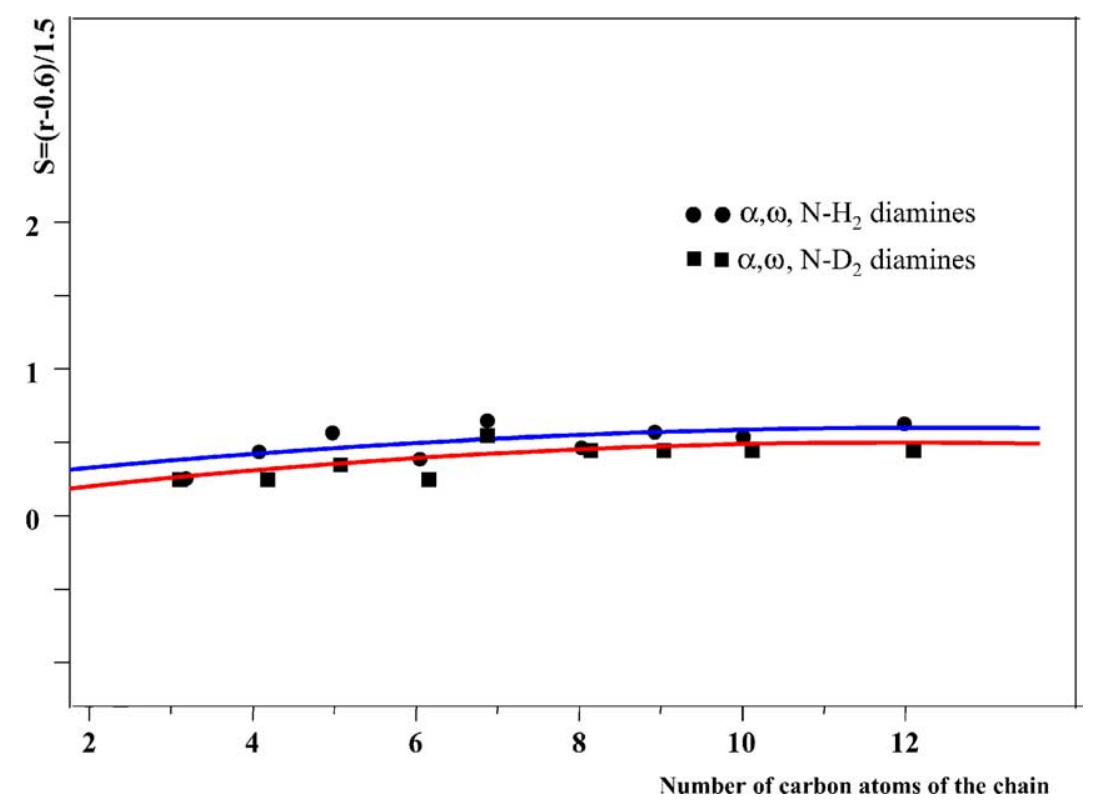

Fig. 6. $S_{\text {lateral }}$ values for $\alpha, \omega-\mathrm{N}-\mathrm{H}_{2}$ and $\alpha, \omega-\mathrm{N}-\mathrm{D}_{2}$ diamines as a function of the number of $\mathrm{CH}_{2}$ groups in the aliphatic chain.

structure and the order due to coupling between adjacent chains [2]. For that they have proposed a semi-quantitative parameter which allows us to get some insight into the amount of lateral crystalline interactions. From experimental results for hexadecane they found that the effect of interchain vibrational coupling and the effect of phonon dispersion due to chain shortening when gauche isomers are formed have the same magnitude upon the whole decrease in intensity of the antisymmetric mode formation. On this basis, they concluded that the distortion parameter could be represented by the following equation

$S_{\text {lateral }}=\frac{(r-0.7)}{1.5}$ where $r$ is the $\mathrm{C}-\mathrm{H}$ antisymmetric (ca. $2895 \mathrm{~cm}^{-1}$ ) versus C-H symmetric stretching (ca. $2850 \mathrm{~cm}^{-1}$ ) peak heights ratio.

In Figs. 6 and 7 we present the $S_{\text {lateral }}$ values obtained using Eq. (2), with 0.6 instead of 0.7 as the residual intensity in the liquid we had found for the studied diamines in the liquid state, for solid $\alpha, \omega-\mathrm{N}-\mathrm{H}_{2}$ and $\alpha, \omega-\mathrm{N}-\mathrm{D}_{2}$ diamines, from 1,2-diaminopropane to 1,12-diaminododecane, at corresponding temperatures; and for $\alpha, \omega-\mathrm{N}-\mathrm{H}_{2}$ and $\alpha, \omega-\mathrm{N}-\mathrm{D}_{2}$ 1,6-diaminohexane as a function of temperature.

From these values, it appears that the vibrational coupling between adjacent chains is not much sensitive to the increase of chainlength between 1,3-diaminopropane and 1,12-diaminododecane. The temperature changes seem to have a

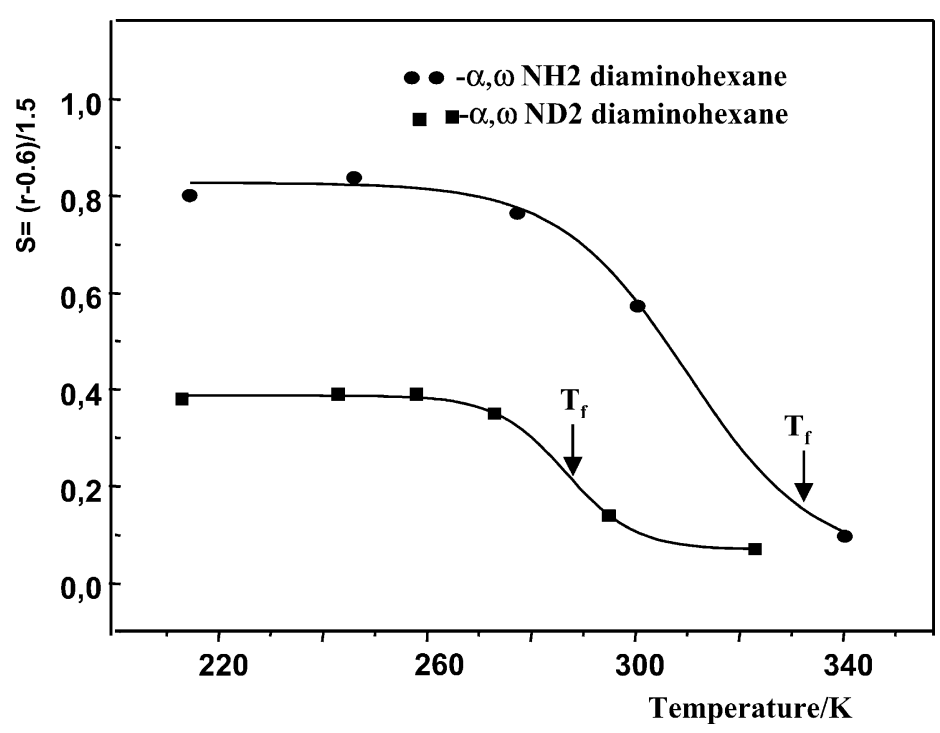

Fig. 7. $S_{\text {lateral }}$ values for $\mathrm{N}-\mathrm{H}_{2}$ and $\mathrm{N}-\mathrm{D}_{2}$ 1,6-diaminohexane as a function of temperature. 
greater influence on the vibrational coupling only on going from the solid to the liquid. In both situations, the $S_{\text {lateral }}$ values for $\alpha, \omega-\mathrm{N}-\mathrm{D}_{2}$ diamines are slightly lower than the $S_{\text {lateral }}$ values for $\alpha, \omega-\mathrm{N}-\mathrm{H}_{2}$ diamines. This result seems to indicate a breakdown in transverse lattice order upon deuteration of the amino groups which can be explained through somewhat different steric effects upon the packing due to the deuterium atoms as compared with the hydrogen atoms.

As measured by the $S_{\text {lateral }}$ parameter defined by Gaber and Peticolas, a value of $S_{\text {lateral }}=0$ corresponds to the lateral order existing in liquid hexadecane whereas a $S_{\text {lateral }}=1$ corresponds to the lateral order existing in solid hexadecane [2]. Thus, from our reported values for the studied diamines these compounds are seen to have a lateral order considerably lower than that of solid hexadecane. A likely result of reduced packing order near the polar head amino groups.

\section{Acknowledgements}

The authors acknowledge financial support from the Portuguese Foundation for Science and Technology, within the Project POCTI/33199/QUI/2000, co-financed by The European Community Fund FEDER.

\section{References}

[1] R.G. Snyder, D.G. Cameron, H.L. Casal, D.A.C. Compton, H.H. Mantsch, Biochim. Biophys. Acta 684 (1982) 111.

[2] B.P. Gaber, W.L. Peticolas, Biochim. Biophys. Acta 465 (1977) 260.

[3] D.A. Pink, T.J. Green, D. Chapman, Biochemistry 19 (1980) 349.

[4] R.G. Snyder, S.L. Hsu, S. Krimm, Spectrochim. Acta 34A (1978) 395.

[5] L.A.E. Batista de Carvalho, L.E. Lourenço, M.P.M. Marques, J. Mol. Struct. 482 (1999) 639.

[6] M.P.M. Marques, L.A.E. Batista de Carvalho, J. Tomkinson, J. Phys. Chem. A 106 (2002) 2473.

[7] A.M. Amorim da Costa, M.P.M. Marques, L.A.E. Batista de Carvalho, Vib. Spec. 29 (2002) 61.

[8] A.M. Amorim da Costa, M.P.M. Marques, L.A.E. Batista de Carvalho, J. Raman Spec., in press.

[9] K. kalyanasundaram, J.K. Thomas, J. Phys. Chem. 80 (1976) 1462.

[10] J.L. Lippert, W.L. Peticolas, Proc. Natl. Acad. Sci. USA 68 (1971) 1572.

[11] A. Sabatini, S. Califano, Spectrochim. Acta 16 (1960) 677.

[12] M.G. Giorgini, M.R. Pelleti, G. Palliani, R.S. Cataliotti, J. Raman Spect. 14 (1983) 16.

[13] L.A.E. Batistsa de Carvalho, L.E. Lourenço, M.P.M. Marques, J. Mol. Struct. 482-483 (1999) 639.

[14] R.A. MacPhail, H.L. Strauss, R.G. Snyder, C.A. Ellinger, J. Phys. Chem. 88 (1984) 334.

[15] S. Abbate, S.L. Wunder, G. Zerbi, J. Phys. Chem. 88 (1984) 593.

[16] H. Okabayashi, T. Kitagawa, J. Phys. Chem. 82 (1978) 1830.

[17] G. Minoni, G. Zerbi, J. Phys. Chem. 86 (1982) 4791.

[18] G. Zerbi, G. Minoni, M.P. Tulloch, J. Chem. Phys. 75 (1983) 5853. 